\title{
Individual and Group Risk-Taking in a Two-Choice Situation ${ }^{1}$
}

\author{
Robert B. Za.tone, Robert .I. Womosin, Myrna A. Wolosin, \\ and Steven J. Sherman ${ }^{2}$ \\ The University of Michigan
}

\begin{abstract}
Individual and group decision making under uncertainty was explored in an attempt to determine whether individual risk preferences change under group conditions. Subjects predicted which of two differentially probable stimulus events would occur, and were paid for correct anticipations in a series of 360 trials. The expected value of the choices was held constant by varying payoff inversely with the frequency of the two events. After 180 trials, individuals either continued alone or were formed into three-man groups. Groups showed consistent and significant shifts in the conservative direction, while individuals remaining alone did not shift. The data were examined in the light of various group-decision models and in the light of other explanations of the risky-shift phenomenon. Changes in individual risk preferences were interpreted as deriving from a change in subjective utilities of outcomes which occurs in the group situation.
\end{abstract}

Recent work in experimental social psychology has identified a phenomenon known as the "risky shift," which occurs when individuals, first independently and then as groups, make choices between uncertain alternatives. The gencral and compelling finding has been that the level of risk-taking is enhanced by the group situation. An extensive review by Kogan and Wallach (1967a) summarizes the research on risky shift and examines a number of explanations offered by various workers to account for the findings in this area. It has been proposed, for instance, that a risky orientation is socially more desirable than caution. This hypothesis assumes that risk preferences of individuals taken one at a time are lower than the risk that their culture expects of them. The group situation makes the cultural value of risk salient by requiring public commitment from the individual, who therefore adjusts his risk level upward. This hypothesis has been challenged by Bem, Wallach, and Kogan (1965) who

${ }^{1}$ This rescarch was supported by the Office of Naval Research, Contract NONR1224(34) NR 170-309.

${ }^{2}$ Now at Indiana University. 
found no risky shift when individuals anticipated that their personal decisions would be disclosed to other group members.

In a similar vein, Brown (1965, p. 701) suggested that just because group discussion about matters of uncertain outcomes makes the value of risk salient, and because it displays the distribution of individual risk preferences, once in a group, the more cautious members discover that their risk levels are substandard. Having this new information, they conform to what they now think is the norm. But when inclividuals are provided with information about the decisions of others in the group, either no shifts or minimal shifts are found (Kogan and Wallach, 1967e; Teger and Pruitt, 1967; Wallach and Kogan, 1965). The third explanation assumes that the group situation allows the individual to gather more information about the alternatives, and hence leads to more rational courses of action. This explanation, therefore, also assumes that risky decisions are more rational than conservative decisions-an assumption which Kogan and Wallach (1967a) reject. Moreover, experimental results show that explicit information about the consequences of the alternative courses of action is not, by itself, a sufficient condition for a risky shift (Bem, Wallach, and Kogan, 1965; Wallach, Kogan, and Bem, 1964). Kogan and Wallach (1967a) also reject the "sympathy" explanation which holds that if one "knows that others who agree with his views will be present when the consequences of his decisions are experienced, he may be willing to accept a greater risk of failure than would otherwise be the case" (Kogan and Wallach, 1967a, p. 254). First, they have shown that presence of others alone could not produce a risky shift (Wallach and Kogen, 1965). And secondly, they found that when individuals expected to suffer the aversive consequences of their decisions with others of like fate, conservative rather than risky shift was obtained (Bem et al., 1965). The fifth explanation of risky shift postulates that initial risk level of individuals is correlated with leaderehip and influence, and that those who are initially riskier are also more influential. And indeed, Clausen (1965), Flanders and Thistlethwaite (1967), Wallach, Kogan, and Bem (1962), and Wallach, Kogan, and Burt (1965) have found positive correlations between initial risk level and perceived influence. But Kogan and Wallach argue that these correlations may rellect a consequence of risky shift, rather than its cause. Regardless of the reasons why a group changes toward a riskier course of action, the risky individual will necessarily be perceived as more influential. The leadership hypothesis is further contradicted by the results of Kogan and Wallach (1967b) who found a negative (although nonsignificant) correlation between initial risk and perceived influence in groups that manifested minimal risky shifts.

The explanation favored by Kogan and Wallach (1967a) invokes the 
concept of diffusion of responsibilily. This theory argues that "in a context of group discussion [an individual] feels less personal responsibility for failure in the pursuit of risky options than he would feel if deciding alone" (Kogan and Wallach, 1967a, p. 260). A series of studies (Bem $t$ tal., 1965; Wallach et al., 1964) in which responsibility for decision making was indirectly manipulated gives some support to the theory, but risky shift was obtained in an experiment by Marquis (1962), in which an individual group member was designated as solely responsible for the consecguences of group decision. The diffusion-of-responsibility hypothesis is further contradicted by Atkinson's (1957) theory of risk-taking behavior, which predicts risk-taking as a function of the interaction among motivation, probability of success, and incentive. Atkinson proposed that alternatives involving moderate risk become attractive to those who are motivated by a desire for success, while extremely risky or extremely conservative alternatives are attractive to those motivated by a fear of failure. Fxtensive empirical work supports Atkinson's theory (see, for instance, Atkinson and Feather, 1966). Thus, if the group reduces "personal responsibility for failure," it should also reduce the fear of failure, and hence prompt the risky individual to moderate his risk-behavior. According to Atkinson's theory, only for extremely conservative groups would a risky shift be predicted.

It appears from the above that the risky-shift phenomenon is generally regarded as a change in individual risk preferences which occurs in group interaction. In a recent paper, Kogan and Wallach (1967c) state it as a matter of "clearly established . . . fact that group interaction cnhances individual risk-taking dispositions" ( $p$. 75). The major evidence for this generalization comes from a study by Wallach and Kogan (1965) in which groups discussed hypothetical choices without a requirement for consensus, and in which a significant risky shift was found. More indirect evidence comes from studies in which group members are first tested individually for their risk preferences, are then allowed to interact and reach consensus, and are finally retested for their individual risk preferences after consensus has been reached. These studies, too, show that following consensus, the individual's risk preferences agree more with the group consensus than with his own pre-discussion level (Kogan and Wallach, 1967b). This evidence, however, is insufficient for concluding that group consensus is riskier than the average of individual risk preferences because individual risk preferences have changed in the course of group interaction. Such a change may have been the result of group consensus rather than its cause. For, if a risky group consensus is reached, it canindependently of its causes-influence the individual member's future risk preferences. 
Given the above evidence, the question still may be raised as to whether a change in individual risk preference is a necessary condition of the high levels of risk that characterize group consensus. It can readily be shown that group consensus may be riskier than the average of the individual risk preferences without the individuals' risk preferences changing at all. Consider, for instance, that there are just two alternatives, $A$ and $B$, having equal expected values, between which individuals must choose. One of these alternatives, $A$, is the riskier one; that is, it has a lower likelihood of occurrence than $B$, but a higher payoff. When making these decisions alone, individuals choose $A$ over $B$, with a fixed probability, $p$, the same for all individuals. These individuals are formed into threeperson groups with the requirement that they reach consensus in choosing between $A$ and $B$. If the probability, $p$, of choosing the riskier alternative, $A$, is the same for all group members, then the probability of the group consensus (reached by a majority vote) being also risky, is

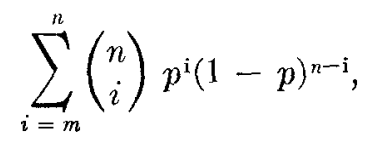

where $n$ is the size of the group and $m$ is equal to $n / 2+.5$ for odd group sizes, and to $n / 2+1$ for even group sizes. If they proceed by majority rule, and if $p$ is equal to .7, let us say, the probability that as a group they will choose $A$, the riskier of the two alternatives, will be .784. Thus, without any changes in individual risk preferences, the group consensus attained by means of a majority decision would have a higher probability of being risky than the average of the individual risk preferences. It is clear from the formula for group decision that if $p$ is greater than .5 , group decision will always exceed $p$, except when $p$ is equal to unity or zero. It is also true, however, that for $p<.5$, the group consensus would be more conservative than the average of the individual risk preferences. The same general result will obtain when the individual probabilities are not the same. For three group members, $i, j, k$, whose probabilities of choosing $A$ are unequal, the probability that the majority will choose $A$ is $p_{i} p_{j} p_{k}+p_{i} p_{j}\left(1-p_{k}\right)+p_{i}\left(1-p_{j}\right) p_{k}+\left(1-p_{i}\right) p_{j} p_{k}$.

If the group operates under different decision schemes, different outcomes would be expected. If, for instance, the group decides on a risky course of action only when all individuals have unanimously chosen it, it will always be more conservative than the average of prior individual risk preferences, except for $p=0$ and $p=1$. For the above example with $p=.7$, the probability of three individuals reaching a unanimous decision in favor of $A$ would be .343 . Smoke and Zajone (1962) have compared various decision schemes, such as majority, quorum, dictatorship, una- 
nimity, oligarchy, etc., for their departure from the average of individual judgments. All of these schemes assume that individual preferences remain constant whether the individual makes decisions alone or as a group member. And all decision schemes except one generate a group solution that substantially differs from the average of individual choices, without these individual preferences changing at all. The exception is the dictatorship by an individual whose risk preference is cqual to that of the average of the remaining group members.

Certain implications follow from considering the above group-decision schemes. If the groups used by Wallach and his co-workers were composed of primarily risky individuals and if they operated under a majority rule, a risky shift would indeed be predicted for them-but not necessarily as a function of changes in individual risk preferences. It is impossible, however, to determine whether individual risk preferences of subjects used in research on risky shift are indeed on the risky side of .5 . Most of the work on this problem has used the so-called "choice-dilemma" task, consisting of 12 hypothetical life situations. In each of the 12 items the protagonist faces a choice between an unlikely but attractive outcome, and one that is less attractive but more likely. The subject chooses the minimum probability of the risky alternative that he would recommend to the protagonist as acceptable. His possible scores on each item are 1, 3, $5,7,9$, and 10. If the individuals were choosing among these scores at random we would obtain a mean of 5.83 on each item, and a total of 69.96 on 12 iterns. A normal distribution of scores would generate an even higher mean and total. It is of interest that almost always individual risk preferences are on the risky side of these figures (Bem et al., 1965; Kogan and Wallach, 1967a; 1967b; Wallach et al., 1965; etc.).

And the riskier are these prior individual risk preferences, the greater is the shift. 'This general observation holds when one compares various conditions within experiments, or when one compares itcms within a given condition (e.g., Siegel and Zajone, 1967; Teger and Pruitt, 1967). It is clear from the formula for majority decision that a positive correlation between initial risk and group consensus would indeed be expected. Teger and Pruitt (1967) interpret Brown's (1965) "value theory" as also predicting a positive correlation between initial risk and the amount of risky shift. They argue that if there is a risky shift on a given item because the consideration of that item elicits the value of risk, then the consideration of that item by the isolated individual should also prompt him toward the riskier alternatives. And, of course, if the consideration of another item elicits the value of caution, the individual's prediscussion choice should tend toward conservative alternatives. Trger and Pruitt (1967) also note that such correlations are at best irrelevant to the theory 
that postulates diffusion of responsibility. While this last observation is correct, the argument that positive correlations between initial risk and risky shift support Brown's "value theory" is not entirely convincing. If the individual tends toward risky (or conservative) alternatives because the item elicits the value of risk (or caution), it is also possible to conclude that he will be less influenced by the group. This conclusion follows from the assumption that the elicitation of the value by the item makes the norm clear and provides a reference for the individual's choices. His decision under these conditions is firm and fixed, and the group should have a greater influence over him on items on which he is unclear.

In the present study a number of individuals are given experience with two alternatives that have uncertain outcomes of fixed probabilities and of equal expceted values. The individuals choose between these alternatives and expcrience the consequences of their decisions directly and immediately. Moreover, these events are repeated on a large number of occasions. After a number of trials, subjects in one condition are formed into groups of three and reach joint decisions. The groups are compared for their risk-taking behavior with individuals who continue working alone for the entire experimental session. An attempt is made to exclude from the decisions factors other than risk. The events about which decisions are made are simple, and their outcomes have presumably only those consequences that are specified to the subjects by the designated arbitrary payoffs. On each trial the subject (or the group) makes a guess about which of two lights will go on, and is paid each time for a correct guess. Since the expected values of the two outcomes are equal, and the probabilities of each event are known, exact predictions for the group consensus can be made assuming various group-decision schemes, such as majority, dictatorship, unanimity, etc. If the obtained data on group consensus should differ from predictions for the various reasonable group-decision schemes, it could be concluded that a change in individual risk preferences occurred when the individual joined the group.

If there is a change in an individual's risk preference, it can occur just because the individual interacts with others, or-under the conditions of the present experiment--because on a series of trials, his group chose risk levels that were at variance with his own, and because these group decisions had consequences that he previously failed to observe. If the consequences of such group decisions are perceived by the individual as favorable, he would be likely to change his risk preference to be more in line with his group. If they are perceived as unfavorable, he will be less influenced. It should be noted that in experiments using the choicedilemma method this latter possibility cannot be examined because the consequences of one's own and one's group's decisions are indeterminate. 
This method differs in several other respects from the standard one used in research on risky shift. In most experiments subjects are not given direct experience with the probabilities or with the payoffs of the alternatives. In the majority of instances they deal with hypothetical situations which are arbitrarily labeled for them as having some designated probability. They are told, for instance, that the heart operation which an hypothetical Mr. B is to undergo has seven out of ten chances of succeeding. But telling the subject about these probabilities may not produce the equivalent subjective probability. It is certainly not the same as having the subject play with a set of dice for a number of trials. Lonergan and McClintock (1961), in what is probably the first study in this area, and Davis, Hoppe, and Hornseth (1966), in a more recent attempt, presented their subjects with rather simple and clear risk situations, and gave them what seemed to be sufficient experience with decisions. Yet in neither study was a risky shift found, although there was an indication in the study carried out by Davis et al. that a group-decision scheme such as plurality may have been operating.

Making decisions about such matters as surgery, one's carecr, etc., involves payoffs that are more complex than the experimental instructions specify. The subjective value of a successful operation, or of a profitable career, may vary tremendously from subject to subject and from time to time for a given subject. There are no ready means for him to quantify these values, so that he can compare them with other subjects with whom he must make joint decisions. Since risk is defined as a function of the probability of the outcome and of its payoff, risk preference can be evaluated only if these elements are well known. One could argue that in making decisions in the choice-dilemma task the subjects employ not only the criterion of risk (as specified by the experimenter) but other criteria as well. It is the purpose of this study to examine a method in which the proportion of factors other than risk in individual and group decision making is minimized.

\section{METHOD}

\section{Subjects}

Forty-eight subjects, all male undergraduates, were recruited from the paid psychology subject pool. A minimum of $\$ 1.25$ per hour was guaranteed. When scheduled, subjects were not told about the purpose of the experiment or that they could earn a greater sum of moncy during the course of the cxperiment.

\section{Apparatus}

Two 1/25-watt lights, mounted on a small panel, served to signal stimulus events. One was marked 1 cent and the other $1 \frac{1 / 2}{2}$ cents. For half of the subjects the left 
stimulus light was associated with the high payoff, and for the remainder, with the low payoff. A punched-tape program controlled the timing and the sequence of stimulus events. Subjects were equipped with switches for making their choices. Stacks of blue and white chips for keeping track of winnings were supplied. Stimulus events and subjects' responses were recorded on an Esterline-Angus Event Recorder.

\section{Design and Procedure}

All subjects were given 360 trials in 12 blocks of 30 . For the first 180 trials all subjects worked alone in isolated 6 - $\times 8$-foot cubicles. In one condition (II), 24 subjects continued as previously for the remaining 180 trials. In another condition (IG), 24 subjects were brought in groups of three to a larger room where they were given the remaining 180 trials.

Upon arriving, the subject was met by the experimenter and led into one of three 6 - $\times 8$-foot cubicles. After a short while, the following instructions were given over an intercom system:

In front of you, you see two lights. Every seven seconds one or the other will go on. You also sce two response plates. During cach 7 -second interval you are to press one plate or the other to anticipate which light will come on. If you press the left plate and the left light comes on, you win 1 (one and a half) cent. If you

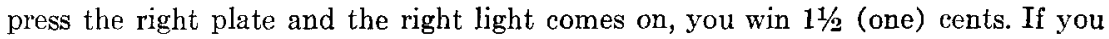
press one plate and the opposite light comes on you win nothing. Also, if you fail to press within the 7 -second interval, you win nothing.

You can keep track of your winnings by the chips which you see in front of you. If you win 1 (one and a half) cent by anticipating the left light, place a white (blue) chip into your bank. If you win $1 \frac{1 / 2}{2}$ (one) cents by anticipating the right light, place a blue (white) chip into your bank. Your winnings will also be kept automatically. We guarantee you a minimum of $\$ 1.25$ per hour and you get to keep whatever you win over that amount; that is, you will get $\$ 1.25$ per hour or your winnings, whichever is more.

The stimulus light marked " 1 cent" had a probability of .6 , and the stimulus light marked " $1 \frac{1 / 2}{2}$ cent" had a probability of .4. The sequence of stimulus events was random, except for the constraint that these probabilities be observed in each block of 30 trials. Stimuli were presented every 7 seconds, and there was a 1 -minute rest period after each trial-block.

$I G$ Condition. At the end of the sixth trial-block subjects in the IG (IndividualGroup) condition were told that the first part of the experiment was over. The experimenter then met all three subjects and led them to a room equipped with apparatus identical to that which they had used in isolation. Instructions were again issued over the intercom:

Again you see the lights and the plates. Now you are working as a team. This time one or the other light will go on every 20 seconds. During this interval the three of you will work together to come to a unanimous decision as to which plate to press. After you decide, one of you will press the plate. [Subject's name] will press for the first set of trials, [another subject's name] for the second, [the third subject's name] for the third, again for the fourth, ete.

Once again, if you press the left plate and the left light comes on, each of you wins 1 (one and a half) cent. If you press the right plate and the right light comes on, each of you wins $1 \frac{1 / 2}{2}$ (one) cents. If you press one plate and the other comes on, or if you fail to press within the 20 -second interval, each of you wins nothing. 
Either you all win or all lose on every trial. Again, you can kecp track of your winnings by placing the appropriate chips in your bank.

Six blocks of 30 trials, each separated by 3 -minute intervals between the blocks, were given. As announced to the subjects, there was a 20 -second intertrial interval.

II Condition. At the end of the sixth trial-block subjects in the II (IndividualIndividual) condition were told that the first part of the experiment was over. They were then taken out of their cubicles by the experimenter and allowed to relax for about 3 or 4 minutes. They were not permitted, however, to speak to one another. After the rest period, they were ushered back to their cubicles and continued as previously for six blocks of 30 trials.

After the experimental session, an explanation of the experiment was given, and the subjects were paid their wages and given their winnings. They were also asked not to speak to their friends or acquaintances about the experiment.

\section{RESULTS}

All the results are reported in percentages of risky choices. Table 1 shows these choices for both experimental sessions and both experimental

TABLE 1

Percentages of Risky Choices Made by Individulas and Groups

\begin{tabular}{lcc}
\hline \multicolumn{1}{c}{ Condition } & First 180 trials & Second 180 trials \\
\hline II (Individual-Individual) & $49.0_{\mathrm{a}}{ }^{\mathrm{a}}$ & $49.8_{\mathrm{a}}$ \\
IG (Individual-Group) & $52.2^{a}$ & $44.6_{\mathrm{b}}$ \\
\hline
\end{tabular}

${ }^{a}$ Means having different subscripts are significantly different from each other at the .01 level. Among the means that share the same subscript no pair is significantly different at the .05 level. Comparisons were made by the Newman-Keuls method.

conditions. Analysis of variance, in which conditions, trials, and sessions were the factors tested, revealcd a significant interaction between conditions and sessions $(F=11.55,1$ and $154 d f, p<.001)$. For the purposes of this analysis, in both experimental conditions groups of three subjects generated data points. In the IG condition, the scores during the first session were the average percentages of risky choices made by the group members individually, and in the second session, they were percentages of risky group decisions. In order to make the reliabilities of the scores in the II condition comparable to those in the IG condition, random groups of three subjects were composed, and the responses of these threeman "groups" were averaged for both sets of 180 trials.

It is also evident from the Newman-Keuls comparisons that the two conditions do not differ from each other during the first 180 trials, and that the II condition shows an unchanged level of risk during the second 180 trials. The difference that emerges as significant is that in the IG condition the proportion of risky choices decreases during the second 180 trials. The final result that is clear from Table 1 is that during the first 
180 trials subjects in both conditions average their responses around $50 \%$. These averages reflect individual scores quite reliably. In the two conditions combined the standard deviation for the first 180 trials was only $8.52 \%$. During the second 180 trials the II subjects continue to choose risky and conservative alternatives with indifference, while the IG subjects shift toward conservatism.

Several discussions were monitored by means of a concealed microphone. In general, very little systematic information could be gathererl by observing them. Typically a member would suggest one alternative, and the others would either indicate consent or make a counterproposal. Arguments were seldom presented and the most frequent reasons given in suggesting a choice were that the suggested alternative had not occurred for a long time, or that it was the more frequent and therefore the more likely one, or that the infrequent one was paying off more, or that the proponent had a "feeling" of being right.

Figure 1 shows percentages of risky choices over the 12 trial-blocks. Trend analyses for the II and the IG groups separately reveal significant quadratic trends ( $F=16.07$ for the II condition and $F=12.05$ for the IG condition, both with 1 and $77 d f$ ). The pattern of choice is thus as

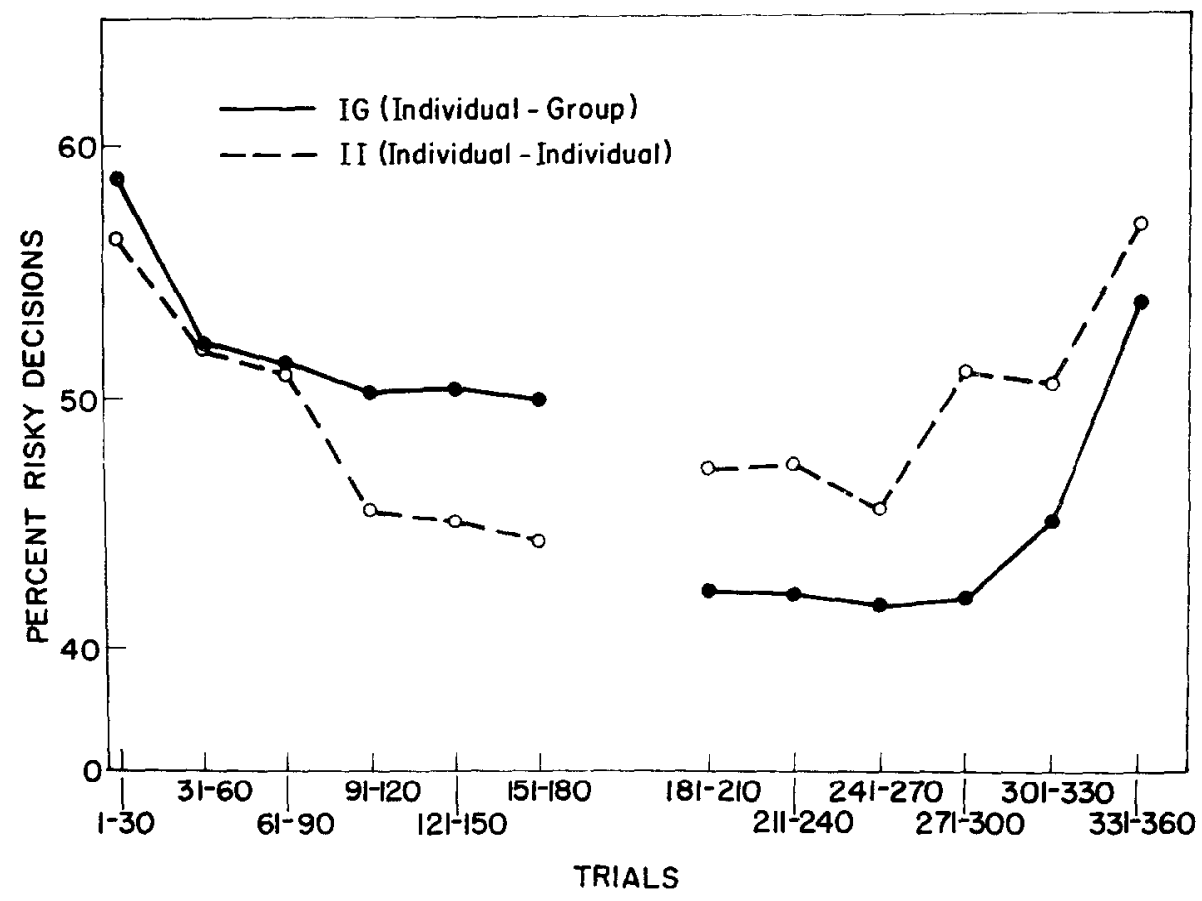

Fig. 1. Percentages of risky decisions in the II and IG conditions. 
stable as it is eurious. Both in the II and the IG conditions subjects begin the series with a distinctive preference for the risky alternative, but already on the second trial-block there is a distinct drop in risk preference. A leveling-off of risk occurs on the third trial-block. In the II group -ubjects continue at about $45 \%$ of risky choices for all but the last two trial-blocks, when riskiness increases. This increase in risky choices is equally true for the IG condition. Subjects in this condition, however, reach an asymptote of 50\% at the close of the individual trials, and groups formed of thesc same subjects drop their risk level to about $42 \%$ on the initial trial-block. We can only speculate about the shape of these curves. The first change in risk level that occurs on the first two or three trial blocks is perhaps simply a learning effect. Subjects start at a relatively high risk level, they discover that they are correct in their guesses only about four out of ten times, and change to a lower risk level. If no other events occurred, they would remain at this level. For subjects who are formed into groups after 180 trials the risk level drops. We shall return to this effect later. But in both the II and the IG conditions there is a rise in risk-taking on the last two trial-blocks. One could perhaps attribute this last rise in risk-taking to a sort of last-ditch attitude. After 300 trials the subject knows that he is approaching the end of the experiment and that he will have only a limited number of trials left. He has bcen winning approximately 18 cents per trial-block, and hence has accumulated only about $\$ 1.80$ during an hour and a half of work. If he continues as previously he can add another 36 cents to his winnings-a sum apparently not satisfying his aspirations. He thus becomes riskier. Having very little to lose, he changes his strategy in favor of risky choices. This conjecture applies less to the II condition, in which subjects also accumulated approximately $\$ 1.80$, but during a much shorter time. Hence, on trial 300 they were less likely to think that the session would soon end.

\section{DISCTSSIOA}

In contrast with most risky-shift studies, in the present experiment groups shifted their risk preferences toward greater caution. This conservative shift was significant and fairly substantial. Out of eight groups, only one shifted in the direction of greater risk. Figure 2 shows data for each group separately, where the consistency of the conservative shifts is apparent. In four cases the group is more conservative than the most conservative of its members (Groups I, II, VI, and VIII), and in three cases the group is more conservative than two of its members (Groups III, IV, and VII). In two of these cases this difference is quite substantial (Groups II and VII). For the group that changes in the direction 

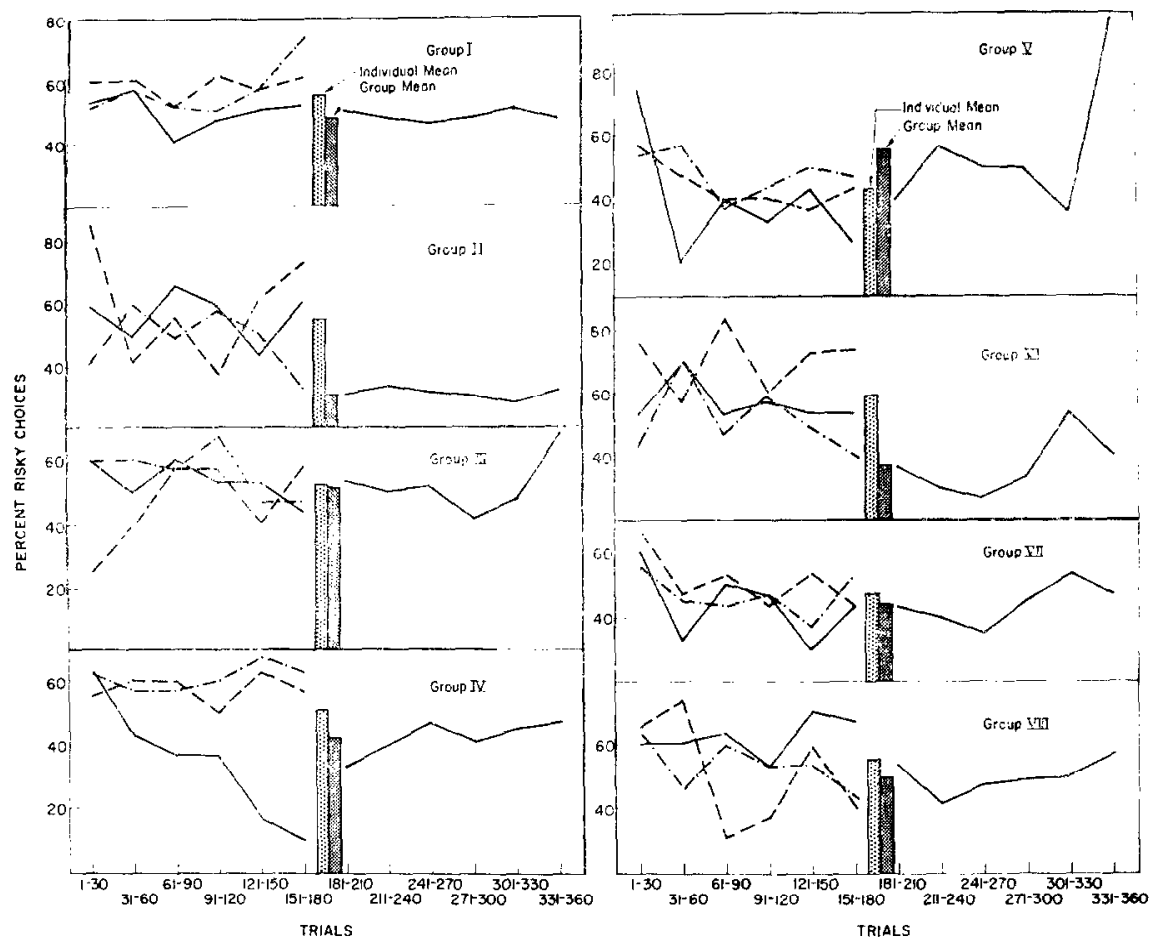

FIG. 2. Individual risk levels and group shifts in risk level (IG condition).

of greater risk (Group V), the shift becomes clearly apparent only on the very last trial-block.

It is also evident from Fig. 2 that, on the whole, individual curves have greater intertrial variability than group curves. In most cases risk preferences of the group are fairly stable, especially between trials 181 and 300 . During the last 60 trials there is a tendency, sometimes rather pronounced, for risk preference to increase, and on the last trial-block three out of the eight groups exceed $50 \%$ of risky choices.

It is possible that, given a greater number of trials, all groups would eventually prefer the risky alternative. This is a matter of empirical question that can be readily ascertained. If the end-of-session rise in risk, however, is associated with a "last-ditch" attitude, a permanent and stable shift toward risk would not occur. In any event, because the same end-of-session rise in risk is observed for individuals working alone, this pattern of results would not constitute solid evidence in favor of the diffusion-of-responsibility theory.

While the data are in clear conflict with previous results on risky shift, they are equally in conflict with the group-decision models discussed in 
the introduction. In six out of the eight groups the majority of the team members, as individuals, preferred risky to conservative choices (Groups I, II, III, IV, VI, and VIII). Yet, in all these cases, the group consensus was more conservative than the individual average.

Majority-decision models also predict that the degree of risky shift is a positive function of the degree of individual risk preference, and therefore one would expect a positive correlation between the average of individual risk preferences and the extent of risky shift. The results, to the contrary, show a correlation of -.79 , significant at the .01 level. Figure 3 plots shifts in risky choices against averages of individual risk preferences, and it is clear from these data that this relationship is rather strong. Our figures are in stark contrast with the Teger-Pruitt coefficients, which vary between .51 and .78 .

Of course, simple majority is not the only decision scheme that groups may use in making choices under the present experimental conditions. It

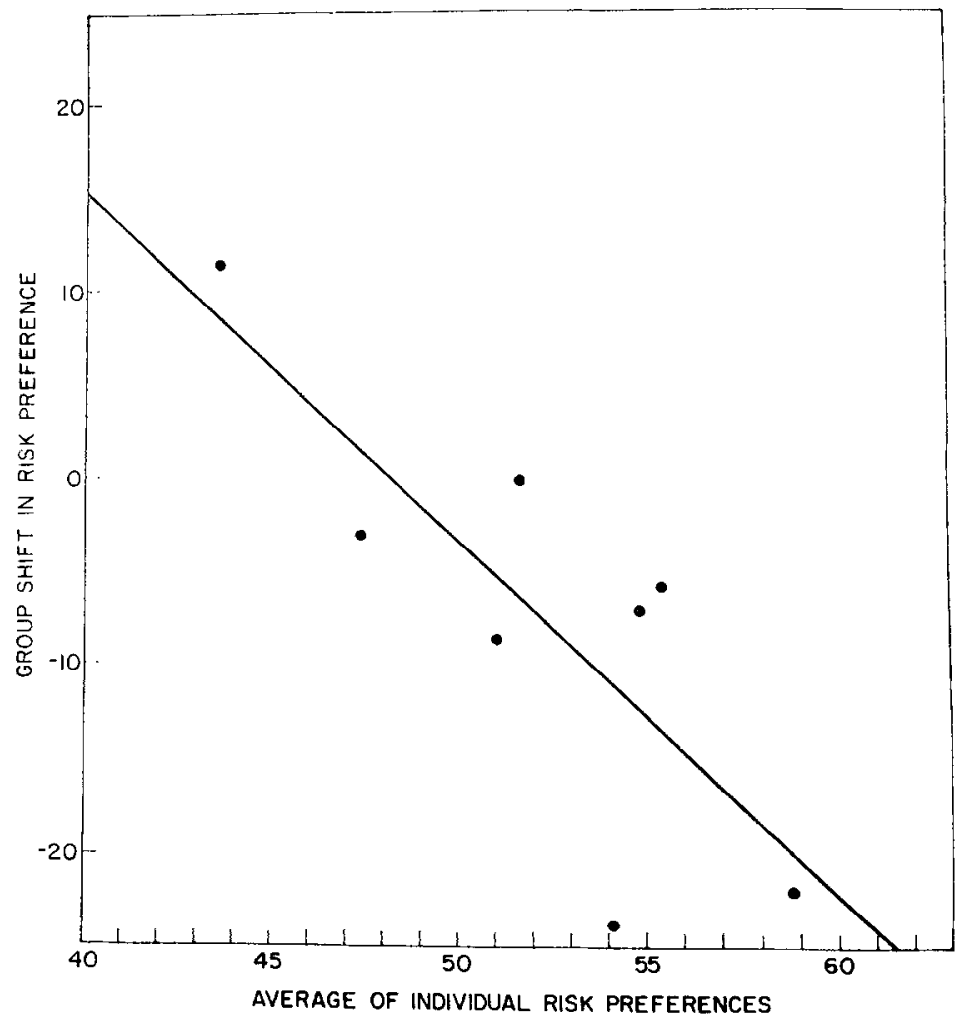

FIG. 3. Shifts in percentage of risky decisions plotted as a function of initial risk preferences. 
is possible, for instance, that a particular individual member determines the group decision completely. We would have here a form of dictatorship, and a systematic prediction could be obtained once we knew how to select the individual who dictates group decision. A reasonable guess would be to suppose that the most conservative member determines group decision completely. We have computed predictions based on various groupdecision schemes, and it is evident that nothing of this sort took place in the present experiment. These predictions (always based on the totality of individual trials), together with the obtained results, are shown in Table 2. It is clear from the sums of squared deviations that neither the

TABLE 2

Group Risk Preferences in Percentages Predicted bx Variots GrottP-Dectsion Schemes

\begin{tabular}{|c|c|c|c|c|c|c|c|c|c|}
\hline \multirow[b]{2}{*}{ Decision scheme } & \multicolumn{9}{|c|}{ Group } \\
\hline & $\Sigma D^{2 a}$ & I & II & III & $\mathrm{IV}$ & $y$ & VI & VII & VIII \\
\hline \multicolumn{10}{|l|}{ Dictatorship of the } \\
\hline conservative member & 886.25 & 49.7 & 48.0 & 45.7 & 34.6 & 39.4 & 51.2 & 43.9 & 50.6 \\
\hline moderate member & 1448.97 & 56.6 & 55.7 & 53.4 & 57.5 & 43.9 & 5.5 .0 & 46.7 & 53.3 \\
\hline risky member & 2796.79 & 58.2 & 58.7 & 56.1 & 60.9 & 47.8 & 70.3 & 51.1 & 62.2 \\
\hline highest winner & 1419.23 & 49.7 & 58.7 & 53.4 & 34.6 & 47.8 & 51.2 & 51.1 & 62.2 \\
\hline Simple majority rule & 1796.75 & 57.3 & 56.2 & 52.6 & 51.8 & 40.6 & 62.2 & 45.8 & 58.0 \\
\hline Unanimity & 8168.29 & 16.4 & 15.7 & 13.7 & 12.1 & 8.3 & 19.8 & 10.5 & 16.8 \\
\hline Average & 1361.29 & 54.8 & 54.1 & 51.7 & 51.0 & 43.7 & 58.8 & 47.2 & 55.4 \\
\hline Observed scores & & 47.5 & 30.3 & 51.6 & 42.1 & 55.0 & 36.7 & 44.0 & 49.4 \\
\hline
\end{tabular}

${ }^{a} D$ is the difference between the observed and obtained values.

majority scheme nor unanimity was used by the groups to arrive at decisions. It is also clear, at the same time, that the average of individual risk preferences is an equally poor predictor of group decisions. The closest approximation is obtained when we assume that there existed a dictatorship of the most conservative member. But the accuracy of this prediction still leaves much to be desired.

With an equal lack of success other decision schemes were tested for accuracy of prediction. For instance, the minimal quorum for risk is a scheme according to which the group makes a risky decision if at least onc of its members chooses the risky alternative. This decision scheme predicted risky group decisions on 82.2-93.5\% of occasions-a figure substantially at variance with the obtained results. Also tried were several variations of the above schemes in which individual members wcre differentially weighted. But weighting the largest winner or the most ac- 
curate group nember more than the remaining nembers did not result in significant improvement of the predictions.

The conclusion that seems to follow from the above analysis is that there occurs a genuine change in individual risk preferences when groups are formed. That such a change is indeed a function of being in groups is shown by a comparison of the individual risk preferences of the II subjects and the IG subjects. But it is at the same time apparent that the shift in individual choice preferences is not in the direction of greater risk but in the direction of greater caution. One can only speculate about the causes of such a change in individual risk preferences. One strong possibility that suggests itself deals with the fact that in the present situation each group suffers (or enjoys) the consequences of its decisions. Perhaps, when the decision is correct and the group wins, the individual who suggested the given alternative (or who is given most credit for the decision) receives praise for a wise or a lucky choice. On the other hand, the group member who is seen as responsible for a losing choice, must feel some degree of regret for causing two group members to lose some money. Suppose that, when individuals are in groups, the utility of being wrong and the utility of being right become parts of the payoffs. But if these utilities are added to the monetary values of the risky and conservative outcomes (i.c., 1 $1 / 2$ ecnts and 1 cent, respectively), expectcd values of the two alternatives are no longer equal. When the utilities of being right and of being wrong become parts of the payoff, the expected value of the frequent alternative is increased and that of the infrequent alternative is decreased because the individual is more likely to be correct when he chooses the more frequent alternative. If $x$ is the psychological payoff that accrues from being right in the group situation, the expected value of the frequent alternative is equal to $.6 \mathrm{cents}+.6 x$, and that of the infrequent alternative is equal to .6 cents $+.4 x$. It is natural under these circumstances to prefer the frequent alternative.

The results of the above study have shown that the risky-shift phenomenon is not as general and universal as previously might have been supposed. They suggest that it is a different matter to have information about the possible consequences of one's own (or one's own group's) decision, and to experience these consequences directly. The data of this study are in conflict with those from studies where such information was provided (Bem et al., 1965; Wallach et al., 1964). And they are also in conflict with the diffusion-of-responsibility hypothesis. The conditions of the present experiment were optimal for diffusion of responsibility to take place. The decisions were unanimous, there was (very brief) discussion prior to each decision, the groups had time to go over their decision strategies between trial-blocks, each member was given the opportunity 
to operate the choice switch equally often, and the payoffs were distributed equally among members. Yet, even with these optimal conditions, a clear conservative shift was obtained.

The critical problem that still remains in explaining the risky-shift phenomenon is whether there are genuine changes in individual risk preferences when the individual joins a group. Among past studies the clearest indication of a change in individual risk preferences as a function of joining a group was obtained in a study by Wallach and Kogan (1965). In one condition of their experiment, groups of individuals did engage in a discussion about their individual decisions, but they were not required to reach consensus. Following discussion, they were simply asked to respond to the choice-dilemmas for the second time. A significant risky shift was found for these individuals, as well as for those who engaged in a discussion and were required to reach consensus. Moreover, the magnitude of these shifts did not differ as a function of the requirement for consensus. It is possible, however, that the Wallach-Kogan results are partly contaminated by experimenter demands. In the critical condition, after the discussion, the subjects were told the following:

All right. That was a good discussion. Several different points of view wcre expressed. For some of you, the discussion may have raised issues that you had overlooked when filling out the questionnaire individually. Now, we would like to find out whether the discussion influenced your judgment in any way. When making your decision now, don't feel bound by what you did when filling out the questionnaire for the first time. We're not interested in your prior opinion, but rather in just how you feel about the situation now. If you still feel the same way, that's quite all right, but we should like you to consider each situation in the light of the discussion. As I told you before, we're interested in seeing how much diversity of opinion is generated by each situation. $O b$ viously, the expression of such diversity should have some impact on everyone's personal opinions. ${ }^{3}$ All right, go ahead and make your decisions for the first situation-the one you just discussed (Wallach and Kogan, 1965, p. 10).

The fourth and the penultimate scntences of these instructions communicate rather strong demands. It is true, however, that while they contain an expectation of change, they do not specify the direction of this change. But perhaps this direction is implied in the descriptions of the choice-dilemmas. The subject is asked to indicate "the minimum odds of success [he] would demand before recommending that the more attractive or desirable alternative, $x$, be chosen." Thus the experimenter also desig-

${ }^{3}$ Italics ours. 
nates which of two alternatives is the more attractive and desirable. Moreover, the choice-dilemmas are usually so stated that the less attractive alternative is often unclear as to its probabilities or its payoff. In item No. 1, Mr. A's salary will not "increase much before he retires"; in item No. 2, Mr. B's heart ailment would force him "to change many of his strongest life habits"; in item No. 5, the weaker alternative consists of "building another plant in the U.S., where there would be moderate return on the initial investment"; in item No. 6, it consists of entering university $\mathrm{Y}$, which "has much less of a reputation in chemistry," but which makes the attainment of a $\mathrm{PhD}$ a mere routine; in item No. 7, the conservative alternative is unspecified; in item No. 9, Mr. J. chooses between staying in a prisoner-of-war camp or escaping, but the subject does not know whether the war will soon end and Mr. J will be liberated, etc.

While it is possible that a change in individual risk preferences has occurred in the present experiment, the explanation we suggested above implies not a change in risk preferences, but a change in the utilities of outcomes. We assumed, namely, that the total payoff for a given outcome consists of the monetary gain established by the experimenter and the psychological reward deriving from being right. We have further suggested that the second component of the payoff becomes considerably more significant in the group situation. Hence, the change occurred not in risk preferences but in the subjective utility of the alternatives. In a sense, the theory of diffusion of responsibility also assumes a difference in the utilities of outcomes, for it suggests that the negative utility of failure is not as great when the failure is shared with others. Future research will profitably concentrate upon the problem of determining (a) if there is a shift in individual preferences when individuals make decisions in groups; (b) if such changes are genuine changes in individual preferences for risk, or changes in the subjective utilities of outcomes; and (c) under what conditions risky-shift phenomena occur without changes in individual risk preferences.

\section{REFERENCES}

Atkisson, J. W. Motivational determinants of risk-taking behavior. Psychological Review, 1957, 64, 359-372.

Atrinson, J. W., and Feather, N. T. (Eds.) A theory of achievement motivation. New York: Wiley, 1966.

Bem, D. J., Wallach, M. A., and Kogan, N. Group decision under risk of aversive consequences. Journal of Personality and Social Psychology, 1965, 1, 453-460.

Brown, R. Social psychology. New York: The Free Press, 1965.

Clausen, G. S. T. Risk taking in small groups. Unpublished doctoral dissertation. Univ. of Michigan, 1965. 
Davis, J. II., Hoppe, R. A., And Hornseth, J. P. Risk-taking: Task, response pattern, and grouping. Paper read at the Midwestern Psychological Association convention, Chicago, 1966.

Flanders, J. P., and Thistlethwaite, D. L. Effects of familiarization and group discussion upon risk taking. Joumal of Personality and Social Psychology, 1967, 5, 91-97.

KogaN, N., AND WALLACH, M. A. Risk taking as a function of the situation, the person, and the group. In New directions in psychology III. New York: Holt, Rinehart and Winston, 1967. (a)

KoGan, N., and WaLlaCh, M. A. Group risk taking as a function of members' anxiety and defensiveness levels. Journal of Personality, 1967, 35, 50-63. (b)

KogaN, N., and Waldach, M. A. Risky-shift phenomenon in small decision-making groups: A test of the information-exchange hypothesis. Jaurnal of Experimental Social Psychology, 1967, 3, 75-84. (c)

LoNerGan, B. G., aNd MCChintock, C. M. Effects of group membership on risktaking behavior. Psychological Reports, 1961, 8, 447-455.

Marquis, D. G. Individual responsibility and group decisions involving risk. Industrial Management Review, 1962, 3, 8-23.

Siegel, S., ANd Zajonc, R. B. Group risk-taking in professional decisions. Under editorial review with Sociometry.

Smoke, W., ANd Zajonc, R. B. On the reliability of group judgments and decisions. In J. Criswell, H. Solomon, and P. Suppes (Eds.), Mathematical methods in small group processes. Stanford, Calif.: Stanford Univ. Press, 1962.

Teger, A. I., AND Pruits, D. G. Components of group risk taking. Journal of Experimental Social Psychology, 1967, 3, 189-205.

Wallach, M. A., and Kogan, N. The roles of information, discussion, and consensus in group risk taking. Joumal of Experimental Social Psychology, 1965, 1, 1-19.

Wallach, M. A., Kogan, N., and BeM, D. J. Group influence on individual risk taking. Journal of Abnormal and Social Psychology, 1962, 65, 75-86.

Wallach, M. A., Kogan, N., and Bem, D. J. Diffusion of responsibility and level of risk taking in groups. Joumal of Abnormal and Social Psychology, 1964, 68, 263-274.

Wallach, M. A., Kogan, N., and Burt, R. B. Can group members recognize the effects of group discussion upon risk taking? Journal of Experimental Social Psychology, 1965, 1, 379-395.

(Received May 15, 1967) 